\title{
The international Glycoconjugate organization awards
}

\section{Sandro Sonnino ${ }^{1}$}

Published online: 2 July 2019

(C) Springer Science+Business Media, LLC, part of Springer Nature 2019

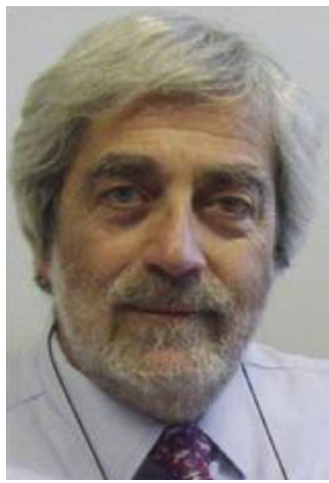

The International Glycoconjugate Organization (IGO) Established two awards that are assigned at the opening ceremony of its biannual International Symposium on Glycoconjugates.

In the far 1995, the 13th International Symposium on Glycoconjugates, the Glyco13, was organized by Professor Sen-itiroh Hakomori in Seattle, WA, USA. The symposium was very successful and registration fee collected by an incredible large attendance together with a substantial fundraising allowed to establish a permanent IGO Award to be "assigned to a glycoscientist who has clearly advanced the field of glycoscience and shows promise of continuing advancements." The award was assigned for the first time 2 years later, in 1997, during the Glyco14.

The following is the list of the awarded.

2019 Richard Cummings (USA)

2017 Pauline Rudd (Ireland)

2015 Taroh Kinoshita (Japan)

Sandro Sonnino

sandro.sonnino@unimi.it

1 Department of Medical Biotechnology and Translational Medicine, University of Milan, Milan, Italy
2013 Kurt Drickamer (United Kingdom)

2011 Jeffrey Esko (USA)

2009 Markus Aebi (Switzerland)

2007 Ajit Varki (USA)

2005 Anne Dell (United Kingdom) and Konrad Sandhoff

(Germany)

2003 Pamela Stanley (USA)

2001 Naoyuki Taniguchi (Japan)

1999 Michael A.J. Ferguson (United Kingdom)

1997 Gerald W. Hart (USA)

In 2011, the IGO decided to establish the IGO Young Glycoscientist Award to be "assigned to an early career glycoscientist who has advanced the field of glycoscience and shows promise of further achievements." The award was assigned for the first time 2 years later, in 2013, during the Glyco22.

The following is the list of awarded.

2019 Nichollas Scott (Australia)

2017 Yoann Rombouts (the Netherlands)

2015 Xin Chen (China)

2013 Amanda Lewis (USA) and to Wen Yi (China).

The Glycoconjugate Journal, as the official journal of the International Glycoconjugate Organization, likes to introduce the 2019 IGO Awarded Richard Cummings and the IGO Young Glycoscientist Awarded Nichollas Scott with a presentation of the IGO President Jin Won Cho and with a their paper summarizing the main results of their researches.

Sandro Sonnino

Editor-in-Chief

Glycoconjugate Journal

Publisher's note Springer Nature remains neutral with regard to jurisdictional claims in published maps and institutional affiliations. 